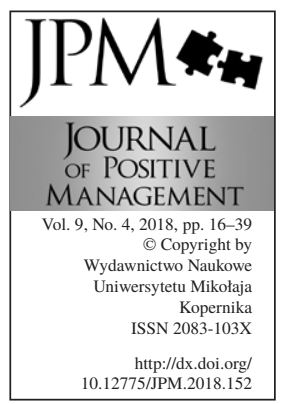

\title{
CULTURE, COMPANIONSHIP AND ACTIVITY-TRAVEL BEHAVIOR: A COMPARISON BETWEEN BEIJING (CHINA) AND UTRECHT (THE NETHERLANDS)
}

\author{
Yanwei Chai \\ College of Urban and Environmental Sciences, Peking University, Beijing, \\ China \\ e-mail: chyw@pku.edu.cn
}

\begin{abstract}
There is a long history of drawing a large cultural distinction between West and East based on the constructs of individualism and collectivism. This coincides with a growing awareness of urban spatial change from the perspective of activity-travel behavior. However, limited attention has been paid to this issue. This paper contributes to the literature on how to examine cultures by investigating companion choice in travel behavior based on activity diary surveys collected in Beijing (China) and Utrecht (the Netherlands). The results show that participants in Beijing travel more often with family members, whereas those in Utrecht tend to travel alone or with friends. These important differences are mediated through sociodemographic, travel purpose and transport mode. The findings provide evidence that collective behavior is popular in Eastern society, whereas individualistic behavior is prevalent in Western society. These results will hopefully stimulate further analysis of cultural differences in transportation policy.
\end{abstract}

Keywords: cultural difference, companionship, activity-travel behavior, China, the Netherlands

Paper type: Reseach paper

\section{Introduction}

Today, people living in different societies are likely to experience their environments differently.

These differences are often rooted in cultural orientations, such as individualism and collectivism.

Scholars conceptualize individualism as the opposite of collectivism when comparing American/European with East Asian cultural frameworks (Oyserman et al., 2002; Oyserman and Lee, 2008). Individualism is assumed to be prevalent in industrialized Western societies, which have deep cultural roots in Christian elements and have experienced religious decline (Dogan, 2002) with the 
popularization of personalized social networks (Inglehart and Baker, 2000). However, East Asian countries, particularly China, have more traditional societies with Confucian cultural heritages. Although China has undergone rapid economic development and reform, traditional Confucian moral understanding dominates in modern society because of path dependency (Inglehart and Baker, 2000) in the form of familybased social networks (Fan, 2011; Leung, 2010).

How cultural and social environments influence activity-travel behavior has not been thoroughly investigated, but it has become a popular topic in transport and geography research (Hanson, 2000; Schwanen, 2008). Culture as a 'way of life' is thought to be invisible in everyday life (Fiske, 1992), representing what people 'just do'. Habits affecting the choice of travel mode are predominantly influenced by, for example, car use lifestyle, cycling culture, walking identity (Aldred and Jungnickel, 2014; Clark and Scott, 2013), which are ultimately normalized in public behavioral practice. For example, car-sharing policies provide not only economic value but also environmental benefits. Nevertheless, policy evaluations should seriously consider cultural issues. People may easily accept car sharing with strangers in an individualistic society, whereas people may tend to use cars with other members of their social networks in a collective society. Thus, the adoptability of transportation policies varies according to place and time (Aldred and Jungnickel, 2014).

Attention to cultural and social contexts in travel behavior indicates that companionship (with whom a person spends time) may represent an important external aspect reflecting cultural differences in urban daily life (Clark and Scott, 2013; Neutens et al., 2008; Srinivasan and Bhat, 2008; Wellman and Wortley, 1990). Companionship in activity-travel behavior may, to some degree, reflect individualistic or collectivistic tendencies. However, it is perhaps surprising that few direct empirical investigations into companionship have been performed in China. Indeed, most have been undertaken in Western contexts (Lin and Wang, 2014). Studies addressing multicultural comparisons are also scarce, particularly regarding activity-travel behavior (Feng et al., 2013). Furthermore, few studies have analyzed travel companion choices in cross-national environments.

In this paper, we argue that the choice of travel companions helps to clarify essential behavioral differences between the West and the East. More importantly, knowledge concerning travel companions in different societies is critical for the accurate evaluation and implementation of novel transportation policies (Lin and Wang, 2014; Moore et al., 2013). For example, policies such as car sharing or high-occupancy vehicle lanes were first proposed in developed countries and later in China. However, these policies must harmonize with Chinese habits regarding companion choice. Further, companionship plays a key role in travel behavior decisions regarding duration, distance and route. The effects of policies cannot be accurately determined if travel companionship is not considered.
CULTURE, COMPANIONSHIP AND ACTIVITY-TRAVEL

Yanwei Chai 
CULTURE, COMPANIONSHIP AND ACTIVITY-TRAVEL

Yanwei Chai
In the empirical section of this study, we perform surveys of 2007 activity diaries collected in Beijing (China) and Utrecht (the Netherlands), which enable us to simultaneously consider influences related to cultural differences and individual preferences. In particular, travel companions are split into (1) core family members, (2) other family members outside the household and (3) friends. Further, this study extends the set of travel purposes from social activities to all types of non-work activities, including shopping, social activities and maintenance, and considers not only car companions but also those in other modes of transport. The empirical study utilizes descriptive methods and multi-nominal models to explore the patterns and mechanisms of travel companion choice.

The rest of this paper is organized as follows. In section 2, relevant studies are systematically reviewed. Then, in section 3, the data used in this paper and model measurements are described.

Section 4 presents a descriptive analysis of companion frequency, and Section 5 gives the empirical results based on model statistics. Finally, the conclusions of the empirical research and insights regarding policymaking and further research are summarized.

\section{Literature review}

\subsection{Cultural differences and daily companionship}

One practical method to measure cultural difference is to focus on individualism and collectivism. "Within individualism, the core unit is the individual; societies exist to promote the well-being of individuals. Individuals are seen separate from one another and as the basic unit of analysis. Within collectivism, the core unit is the group; societies exist, and individuals must fit into them. Individuals are seen as fundamentally connected and related through relationships and group memberships." (Oyserman and Lee, 2008). There is a long history of using this dualistic construct when comparing Western and Eastern cultures. Overall, East Asians have been represented as more collectivistic and less individualistic than Americans and Western Europeans (Oyserman et al., 2002).

The collective norm has a profound impact on Chinese society, which can be summarized in terms of several phenomena: individuals from the same group are supposed to be interrelated; the effective performance of tasks is often based on interpersonal connections; and regarding selfdescription, this norm commonly arises as "I am a member of" a specific group (Leung, 2010). These phenomena are believed to be associated with Confucian thought, a moral system that is deeply rooted in East Asia, particularly in China. In the Confucian social network, family comes first, in line with the old adages "blood is thicker than water" and "children were raised for the security of old age" (Wellman and Wortley, 1990; Zhan and Montgomery, 2003). Collectivistic beliefs in China 
promote tight interactions between parents and children in addition to siblings and extended kin in daily life.

In contrast, individualism is prevalent in Western countries. Although Christianity promotes collective behavior to a certain degree (such as sharing norms found in church), its core values are those of individual choice, personal freedom and self-conception. The striking decline of religious beliefs in the West pulls young generations away from church, and they tend to form moral norms according to personal networks, which further leads to the unconscious influence of individualism (Dogan, 2002; Houtman and Mascini, 2002). Membership in social networks is open to close friends with similar norms (Phan et al., 2009). Relatively frequent contact with non-family members occurs after ensuring necessary care is provided for family members (Komter and Knijn, 2006).

Because cultural differences are difficult to observe in daily life, companionship as a practical dimension is key in bridging daily behavior and cultural context. Companionship relates to the inherent desire to perform activities or travel with others out of necessity or voluntarily to obtain support, information, a sense of belonging and safety. Compared to friendship, companionship highlights physical presence when engaging in activity-travel behavior. Companionship is thus an important form of social support reflecting interpersonal connection, personal choice, and various characteristics of individualism or collectivism (Wellman and Wortley, 1990). In modern society, the prevalence of individualism reduces opportunities for strangers to make contact, resulting in silence in public spaces or indifference between persons (Bauman, 2005; Beck, 1996). Individualism stimulates people to become aware of collective values, such as interpersonal concerns and engagement in traditional culture (Hui, 1988). Companionship may represent a behavioral practice in the rethinking process. However, most studies focus on psychological discussions and do not address geographical perspectives on how moral thought is reflected in activity-travel behavior.

In activity-travel behavior research, the choice of companions is complex. Considering solo vs. joint behaviors, individualism encourages solo behavior, whereas collectivism promotes joint behavior (Dejbakhsh et al., 2011; Manrai and Manrai, 2011). Further considering the type of companion, collectivism motivates companionship in different ways. Extensive social networks likely lead one to be accompanied by friends, colleagues or even strangers (Srinivasan and Bhat, 2008; Wellman and Wortley, 1990). In contrast, strong family beliefs or family obligations may restrict frequent interactions with family members (Hui, 1988; Leung, 2010).

\subsection{Life status as an important factor regarding companion choice}

Gender is often considered to be an important variable in companion research. First, women tend to foster relationships and maintain networks (Schwanen et al., 2007; Wellman and Wortley, 1990), implying that women tend to provide
CULTURE, COMPANIONSHIP AND ACTIVITY-TRAVEL

Yanwei Chai 
CULTURE, COMPANIONSHIP AND ACTIVITY-TRAVEL

Yanwei Chai emotional support, including companionship. Second, women are responsible for more household work in most countries (Schwanen et al., 2002), such as picking up young children from school and caring for elders, which increases the probability of joint activities (Harvey and Taylor, 2000; Schwanen et al., 2007; Zhan and Montgomery, 2003). Third, men are considered the primary breadwinners in households and thus tend to have priority in making decisions regarding time allocation because of time recourse (Cao and Chai, 2007). For example, men have more freedom to travel alone and participate in out-of-home activities, whereas women have less control over their activities and travels, which tend to be sidelined (Harvey and Taylor, 2000; Schwanen et al., 2008).

The literature addressing life cycle relates it to age, household structure and the presence of young children. Younger and older people tend to have a higher frequency of joint activities (Carrasco and Miller, 2009; Sharmeen and Ettema, 2010), whereas middle-aged groups must balance work and life. Living with a partner and the presence of young children may negatively affect social and recreational activities because time pressures but positively affect joint activities and travel with family members (Carrasco and Miller, 2006; 2009; Lee et al., 2007). Generally, changes in the levels of household responsibilities that people face are associated with changes in companion choice and reduced burdens for solo behavior, whereas connections with family members increases these burdens.

Several studies have recognized the relevance of social status, but the evidence remains ambiguous. First, some studies show that individuals with high income are more social (Carrasco and Miller, 2009), whereas others conclude that these individuals tend to act alone to maximize efficiency and do no care to share resources (Sharmeen and Ettema, 2010). Second, highly educated persons might harbor liberal ideas and self-conceptions and might generally exhibit independent behavior. In contrast, a lower level of education is associated with collectivistic attitudes used to cope with external rules (Wink, 1997). However, some evidence suggests that social interaction may vary between educated groups by activity type (Walker, 1995). Third, employment is related to inter-personal interactions. Some studies report that full-time jobholders with long working hours may exhibit reduced joint behavior with little flexibility (Gliebe and Koppelman, 2002). In contrast, working at home may increase opportunities to engage in various activities (Hubers et al., 2011).

\subsection{Interactive strategy for choosing activity companions and travel companions}

Companions can be divided into activity companions and travel companions with interactive effects. The choice of an activity companion is based on the type of companion with whom one desires to interact, and this desire is motivated by the activity itself or the value of the activity. The desire to travel is thought 
to derive from activity desire. The travel companion thus reflects two aspects: one is demand for company during the activity, and the other is the necessity of performing activities based on altruism, such as accompanying a child to school, as performed within a household (Gliebe and Koppelman, 2002). The choice of both immediate activity companions and previous travel companions is related to the purpose of the activity, whereas the choice of both following activity companions and immediate travel companions is related to the transport mode.

Companion choices vary according to the travel purpose. Social and recreational activities and travel have a social dimension because they only take on meaning when shared with others (Harvey and Taylor, 2000). Most attention has been paid to the impacts of the composition and structure of social networks on the frequency of social and recreational activities (Ettema and Zwartbol, 2013). Carrasco and Miller (2006) found that the composition features (such as the number of family members or friends, and strong or weak ties) impact participation in activities related to hosting/visiting or bars/restaurants. A later study found that network structure (including components, density, and centrality) crucially influences recreational frequency (Carrasco and Miller, 2009). Some scholars expand activity types beyond social and recreational purposes. The characteristics of joint behavior in work, shopping, leisure and social settings are known to vary with activity type and companion type (Ettema and Kwan, 2010; Srinivasan and Bhat, 2008). Some studies on household time-use patterns have extended the categories into subsistence, maintenance and discretionary to discuss family members' joint participation (Gliebe and Koppelman, 2002; Lee et al., 2007).

The availability of the transport mode is another crucial element in companion choice. Within a household, car use is a trade-off when family members simultaneously wish to use one vehicle, which is resolved by decreasing out-ofhome activities or rescheduling to allow sharing (Miller et al., 2005). Competition is less common in multi-car households (Gliebe and Koppelman, 2002). Beyond the household, companionship is associated with car-pooling, which entails having multiple people in one car to reduce total amount of driving (Fellows and Pitfield, 2000; Gärling et al., 2000). Good access to a public transport system facilitates opportunities for social contact. However, slow transport modes may indirectly initiate companionship because of traffic jams and discouraging policies (Schwanen et al., 2002). Recent studies indicate the importance of cultural specificity and social identity in shaping slow transport practices. Cycling, for example, is linked to the Dutch identity (Pelzer, 2010), whereas the UK displays low cycling rates (Aldred and Jungnickel, 2014). Furthermore, the presence of companions increases walking or cycling practice (Clark and Scott, 2013).

Spatial accessibility is also related to companionship. Physical proximity positively influences face-to-face interactions (Carrasco and Miller, 2009). 
CULTURE, COMPANIONSHIP AND ACTIVITY-TRAVEL

Yanwei Chai

Figure 1. Schematic presentation of the conceptual model Source: own work.
Recreational engagement with family members is increased by easier access to parks (Fan and Khattak, 2009). The companion choice for non-work activities based on facility accessibility differs by activity type (Sharmeen and Ettema, 2010). Additionally, information and communication technologies (ICTs) may change daily behavior. However, the implications are complex and depend on the purpose of the activity or the persons involved (Schwanen and Kwan, 2008).

In summary, the existing literature reports differences in companion choice based on cultural backgrounds with respect to socio-demographics, life cycle, travel purpose and transport mode. However, little attention has been paid to differences between travel companions from different cultures, in addition to the influential mechanism of individual behavior choice. After considering possible factors, we expect that people in an individualistic society will tend to act alone and will be more likely to interact with friends if accompanied. In contrast, people in a collectivistic society tend to act jointly, particularly with family members. We will therefore systematically address variations in companion choice in the societies below. Our framework is shown in Figure 1.

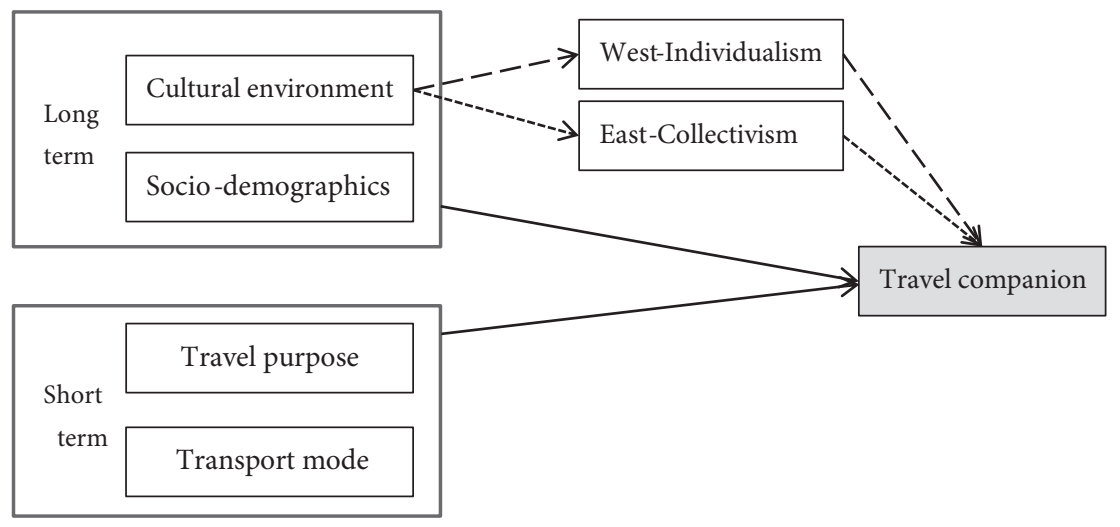

\section{Survey design}

\subsection{Data and study area}

The empirical analyses are based on two datasets from Beijing (China) and Utrecht (the Netherlands). The first dataset was collected in the Beijing Metropolitan region, inside the $6^{\text {th }}$ ring road. Two-day activity diaries were collected in Beijing in October 2007. The survey consisted of a combination of face-to-face interviews and questionnaires. We selected 10 neighborhoods that varied according to location, size and composition of residents. We then randomly selected 60 households in each neighborhood. In total, the dataset contains data from 520 
households and 1,119 individuals. Detailed survey information is provided in Wang, Chai, and Li (2010). The second dataset was collected among one- and dual-earner households in the Utrecht-Amersfoort-Hilversum area in FebruaryJuly 2007. A total of 26 neighborhoods were selected based on systematic variation in terms of income level, urban density and accessibility to public transport. Surveyed households were randomly drawn from digital files, and 1,010 households returned the selection questionnaires (of 13,500 sent) and were willing to participate in the main survey. Finally, 742 respondents completed the two-day questionnaire, which included activity, travel and communication diaries. Detailed survey information is provided in Hubers et al. (2011).

From the original datasets, the following participants were included: (i) participants who provided gender, age and income information (20 excluded in Beijing and 18 in Utrecht); (ii) participants who filled out the diary for two days (303 excluded in Beijing and 49 in Utrecht); (iii) participants who provided accurate information on companionship and meeting places ( 8 excluded in Beijing and 61 in Utrecht); and (iv) participants who conducted at least one out-ofhome discretionary activity (79 excluded in Beijing and 35 in Utrecht). Thus, usable diary data from 709 individuals in Beijing and 569 individuals in Utrecht were selected for our analysis.

The usable diary data described above were subjected to the companion analysis (Table 1). The gender composition is relatively balanced. Beijing has a relatively large proportion of young people than Utrecht. In both cities, higher-educated persons are overrepresented because the survey was targeted at professional groups. The share of people with a bachelor's or master's degree amounts to two thirds of our samples in both Beijing and Utrecht. Because of the large gap in income levels between Beijing and Utrecht, we divided the data into two datasets. This income gap may also explain the difference in driving license and car-ownership rates.

Regarding household structure, the high percentage in the 'other' category in Beijing is attributed to the common occurrence of extended households.

\begin{tabular}{llrrrrr}
\hline & \multicolumn{3}{c}{ BEIJING } & \multicolumn{3}{c}{ UTRECHT } \\
\hline \multirow{2}{*}{ Gender } & Frequency & Percent & Frequency & Percent \\
\hline \multirow{4}{*}{ Age } & Male & 375 & 50.4 & 316 & 55.5 \\
\cline { 2 - 7 } & Female & 352 & 49.6 & 253 & 44.5 \\
\cline { 2 - 7 } & $20-29$ & 70 & 9.9 & 32.4 & 114 & 8.1 \\
\cline { 2 - 7 } & $30-39$ & 230 & 186 & 26.2 & 166 & 29.2 \\
\cline { 2 - 7 } & $40-49$ & 173 & 24.4 & 66 & 11.6 \\
\cline { 2 - 7 } & $50-59$ & 50 & 7.1 & & 177 \\
\hline
\end{tabular}

Table 1. Sample profile Source: own work. 
CULTURE,

COMPANIONSHIP

AND ACTIVITY-TRAVEL

Yanwei Chai

Table 1.

continued

\begin{tabular}{|c|c|c|c|c|c|c|}
\hline & \multicolumn{3}{|c|}{ BEIJING } & \multicolumn{3}{|c|}{ UTRECHT } \\
\hline & & Frequency & Percent & & Frequency & Percent \\
\hline \multirow{3}{*}{ Education } & Low & 74 & 10.4 & & 17 & 3 \\
\hline & Middle & 185 & 26.1 & & 174 & 30.6 \\
\hline & High & 450 & 63.5 & & 378 & 66.4 \\
\hline \multirow{2}{*}{$\begin{array}{l}\text { Driving } \\
\text { license }\end{array}$} & Yes & 360 & 50.8 & & 31 & 5.4 \\
\hline & No & 349 & 49.2 & & 538 & 94.6 \\
\hline \multirow{5}{*}{$\begin{array}{l}\text { House- } \\
\text { hold } \\
\text { income } \\
\text { (EUR) }\end{array}$} & $300-$ & 163 & 23 & $2000-$ & 129 & 22.7 \\
\hline & $300-500$ & 173 & 24.4 & $2000-3000$ & 159 & 27.9 \\
\hline & $500-700$ & 166 & 23.4 & $3000-4000$ & 154 & 27.1 \\
\hline & $700-1000$ & 116 & 16.4 & $4000+$ & 121 & 21.3 \\
\hline & $1000+$ & 91 & 12.8 & & & \\
\hline \multirow{4}{*}{$\begin{array}{l}\text { House- } \\
\text { hold car }\end{array}$} & None & 440 & 62.1 & & 74 & 13 \\
\hline & 1 & 239 & 33.7 & & 302 & 53.1 \\
\hline & 2 & 28 & 3.9 & & 172 & 30.2 \\
\hline & 3 & 2 & 0.3 & & 21 & 3.7 \\
\hline \multirow{2}{*}{ Children } & Below 12 & 236 & 33.3 & & 418 & 73.5 \\
\hline & None & 473 & 66.7 & & 151 & 26.5 \\
\hline \multirow{4}{*}{$\begin{array}{l}\text { House- } \\
\text { hold } \\
\text { structure }\end{array}$} & Single & 17 & 2.4 & & 115 & 20.2 \\
\hline & Couple & 152 & 21.4 & & 200 & 35.1 \\
\hline & $\begin{array}{l}\text { Nuclear } \\
\text { family }\end{array}$ & 223 & 31.5 & & 229 & 40.2 \\
\hline & Other & 317 & 44.7 & & 25 & 4.4 \\
\hline Total & & 709 & 100 & & 569 & 100 \\
\hline
\end{tabular}

\subsection{Measurement and operationalization of concepts}

To reflect a free choice of companions, we selected only non-work trips, except for those returning home, because people have more control regarding with whom they perform non-work activities.

The first task is to develop a classification system to organize numerous types of non-work travel purposes to facilitate analytics. Considering the limitations on social and recreational behavior only, we summarize travel purposes into four categories: 1) Shopping: going shopping in stores; 2) Leisure: playing sports, attending parties, or visiting or dining together; 3) Maintenance: caring for others, picking up persons/goods, or going to the post office or bank; 4) Other: e.g., going to church.

The dependent variable, the companion, is defined as belonging to one of four social circles: alone, friend or colleague, core family and other family [1]. 
These social circle categories are deeply meaningful regarding individualistic or collectivistic characteristics. Alone represents the highest degree of individualism; friends represent a relatively high degree of individualism because of the high level of control over companion choice; core family members represent a relatively high degree of collectivism because they are not freely chosen companions; and other family members represent the highest degree of collectivism.

\section{Descriptive statistics of companion frequency}

\subsection{Frequency of activity companions by activity types}

The comparison of activity companions clearly shows that residents in Beijing perform activities alone less often than residents in Utrecht. If accompanied, as the percentages in italics show, people in Beijing tend to choose family members, whereas people in Utrecht choose friends relatively frequently. Considering activities only involving family members, extended family members represent a considerable share of activities in Beijing, whereas this group is unimportant in Utrecht. Consequently, the percentage of core family members accompanying activities is substantially higher in Utrecht than in Beijing. This provides evidence that phenomena related to social individualism are more prominent in Utrecht. Friends take a central place in individuals' social networks in the Netherlands, and people in Utrecht frequently interact with friends. Furthermore, family obligations and physical proximity result in frequent interactions with core family members in Utrecht. Chinese society, however, holds strong family beliefs: family members, both core and extended, play important roles as companions in daily life in Beijing.

There are large differences between Beijing and Utrecht regarding activity types. People in Beijing engage in leisure activities alone more often but other activities less so. This finding derives from the definitions of the above activities. Leisure is actually a mixed category that includes social, recreation, sports and cultural events, resulting in a substantial percentage of unaccompanied episodes. Activities without obvious socializing functions, such as sports and tours, increase the "alone" percentage in Beijing. This also explains the number of companions in the 'other' category, which primarily includes ICT-related activities in Utrecht but is a collective category in Beijing. Furthermore, ICT use results in people performing activities alone and thus promotes an individualistic society (Wellman, 2001). If accompanied, leisure activities are likely to be pursued with friends in both Beijing and Utrecht. However, shopping percentages vary, possibly because shopping is sometimes considered a recreational activity in China, particularly for women. There is a sharp contrast between Beijing and Utrecht regarding family activities. Nearly all percentages involving extended members are low in Utrecht. In contrast, in China, the extended family is thought to be the strongest given 
CULTURE, COMPANIONSHIP AND ACTIVITY-TRAVEL

Yanwei Chai

Table 2. Frequency and percentage of outdoor activity companions in Beijing and Utrecht

Italics in parentheses indicate percentages of accompanied situations.

Source: own work. group. Thus, stronger connections with this group indicates that a family-based network is an important aspect of the social network in Beijing.

Activity companionship is one aspect used to indicate a society's level of individualism. Companionship in Beijing is substantially higher than in Utrecht, suggesting that collectivism is more prevalent in Eastern cities than in Western cities. Modern society is marked by individualism (Beck, 1996). After a prolonged period of modernization, Utrecht has developed into an individualistic society, as confirmed by evidence showing that more than half of the recorded activities were performed alone.

\begin{tabular}{|c|c|c|c|c|c|c|c|c|c|}
\hline & \multicolumn{2}{|l|}{ Alone } & \multicolumn{2}{|c|}{ Nuclear family } & \multicolumn{2}{|c|}{ Other family } & \multicolumn{2}{|l|}{ Friends } & \multirow{2}{*}{$\begin{array}{c}\text { Total } \\
=100 \%\end{array}$} \\
\hline & Freq. & Per. & Freq. & Per. & Freq. & Per. & Freq. & Per. & \\
\hline \multicolumn{10}{|c|}{ BEIJING } \\
\hline Shopping & 249 & $46.7 \%$ & 220 & $\begin{array}{r}41.3 \% \\
(77.5 \%)\end{array}$ & 29 & $\begin{array}{r}5.4 \% \\
(10.2 \%)\end{array}$ & 35 & $\begin{array}{r}6.6 \% \\
(12.3 \%)\end{array}$ & 533 \\
\hline Leisure & 254 & $21.0 \%$ & 339 & $\begin{array}{r}28.1 \% \\
(35.5 \%)\end{array}$ & 129 & $\begin{array}{r}10.7 \% \\
(13.5 \%)\end{array}$ & 486 & $\begin{array}{r}40.2 \% \\
(50.9 \%)\end{array}$ & 1208 \\
\hline Maintenance & 123 & $34.4 \%$ & 139 & $\begin{array}{r}38.8 \% \\
(59.1 \%)\end{array}$ & 40 & $\begin{array}{r}11.2 \% \\
(17.0 \%)\end{array}$ & 56 & $\begin{array}{r}15.6 \% \\
(23.8 \%)\end{array}$ & 358 \\
\hline Other & 39 & $38.6 \%$ & 31 & $\begin{array}{r}30.7 \% \\
(50.0 \%)\end{array}$ & 2 & $\begin{array}{r}2 \% \\
(3.2 \%)\end{array}$ & 29 & $\begin{array}{r}28.7 \% \\
(46.8 \%)\end{array}$ & 101 \\
\hline Total & 665 & $30.2 \%$ & 729 & $\begin{array}{r}33.1 \% \\
(47.5 \%)\end{array}$ & 200 & $\begin{array}{r}9.1 \% \\
(13.0 \%)\end{array}$ & 606 & $\begin{array}{r}27.5 \% \\
(39.5 \%)\end{array}$ & 2200 \\
\hline \multicolumn{10}{|c|}{ UTRECHT } \\
\hline Shopping & 427 & $65.9 \%$ & 179 & $\begin{array}{r}27.6 \% \\
(81.0 \%)\end{array}$ & 12 & $\begin{array}{r}1.9 \% \\
(5.4 \%)\end{array}$ & 30 & $\begin{array}{r}4.6 \% \\
(13.6 \%)\end{array}$ & 648 \\
\hline Leisure & 167 & $13.5 \%$ & 341 & $\begin{array}{r}27.5 \% \\
(31.8 \%)\end{array}$ & 92 & $\begin{array}{r}7.4 \% \\
(8.6 \%)\end{array}$ & 640 & $\begin{array}{r}51.6 \% \\
(59.6 \%)\end{array}$ & 1240 \\
\hline Maintenance & 428 & $42.5 \%$ & 293 & $\begin{array}{r}29.1 \% \\
(50.6 \%) \\
\end{array}$ & 40 & $\begin{array}{r}4.0 \% \\
(6.9 \%)\end{array}$ & 246 & $\begin{array}{r}24.4 \% \\
(42.5 \%)\end{array}$ & 1007 \\
\hline Other & 1330 & $91.3 \%$ & 3 & $\begin{array}{r}0.2 \% \\
(2.4 \%)\end{array}$ & 1 & $\begin{array}{r}0.1 \% \\
(0.8 \%)\end{array}$ & 123 & $\begin{array}{r}8.4 \% \\
(96.9 \%)\end{array}$ & 1457 \\
\hline Total & 2352 & $54.0 \%$ & 816 & $\begin{array}{r}18.8 \% \\
(40.8 \%)\end{array}$ & 145 & $\begin{array}{r}3.3 \% \\
(7.3 \%)\end{array}$ & 1039 & $\begin{array}{r}23.9 \% \\
(52.0 \%)\end{array}$ & 4352 \\
\hline
\end{tabular}

\subsection{Frequency of travel companions by travel purpose}

We also prepared a table showing the results regarding travel companions (Table 3). The percentages in the total columns in Tables 2 and 3 clearly show that traveling alone happens substantially more frequently than participating in activities alone. Thus, traveling with others is substantially more difficult than performing activities with others because people must change their original routes 
to meet their companions' requirements. The circle of core family members occupies the second highest percentage in both cities because they have the same departure point. Friends as travel companions are more important in Beijing than in Utrecht, with $35.1 \%$ trips for leisure purposes with friends recorded in Beijing. In China, friends participate in social and recreational activities by not only meeting at the destination but also traveling there together. Other family members do not constitute the primary companion group in Beijing or Utrecht.

\begin{tabular}{|c|c|c|c|c|c|c|c|c|c|}
\hline & \multicolumn{2}{|l|}{ Alone } & \multicolumn{2}{|c|}{ Nuclear family } & \multicolumn{2}{|c|}{ Other family } & \multicolumn{2}{|c|}{ Friends } & \multirow{2}{*}{$\begin{array}{l}\text { Total } \\
=100 \%\end{array}$} \\
\hline & Freq. & Per. & Freq. & Per. & Freq. & Per. & Freq. & Per. & \\
\hline \multicolumn{10}{|c|}{ BEIJING } \\
\hline Shopping & 260 & $48.7 \%$ & 222 & $\begin{array}{r}41.6 \% \\
(81.0 \%) \\
\end{array}$ & 11 & $\begin{array}{r}2.1 \% \\
(4.0 \%) \\
\end{array}$ & 41 & $\begin{array}{r}7.7 \% \\
(15.0 \%) \\
\end{array}$ & 534 \\
\hline Leisure & 304 & $33.8 \%$ & 369 & $\begin{array}{r}41.0 \% \\
(62.0 \%)\end{array}$ & 17 & $\begin{array}{r}1.9 \% \\
(2.9 \%)\end{array}$ & 209 & $\begin{array}{r}23.2 \% \\
(35.1 \%)\end{array}$ & 899 \\
\hline Maintenance & 129 & $44.9 \%$ & 123 & $\begin{array}{r}42.9 \% \\
(77.8 \%)\end{array}$ & 4 & $\begin{array}{r}1.4 \% \\
(2.5 \%)\end{array}$ & 31 & $\begin{array}{r}10.8 \% \\
(19.6 \%)\end{array}$ & 287 \\
\hline Other & 34 & $42.0 \%$ & 36 & $\begin{array}{r}44.4 \% \\
(76.6 \%)\end{array}$ & 0 & $\begin{array}{r}0.0 \% \\
(0.0 \%)\end{array}$ & 11 & $\begin{array}{r}13.6 \% \\
(23.4 \%)\end{array}$ & 81 \\
\hline Total & 727 & $40.4 \%$ & 750 & $\begin{array}{r}41.6 \% \\
(69.8 \%) \\
\end{array}$ & 32 & $\begin{array}{r}1.8 \% \\
(3.0 \%) \\
\end{array}$ & 292 & $\begin{array}{r}16.2 \% \\
(27.2 \%) \\
\end{array}$ & 1801 \\
\hline \multicolumn{10}{|c|}{ UTRECHT } \\
\hline Shopping & 417 & $68.1 \%$ & 170 & $\begin{array}{r}27.8 \% \\
(87.2 \%) \\
\end{array}$ & 18 & $\begin{array}{r}2.9 \% \\
(9.2 \%) \\
\end{array}$ & 7 & $\begin{array}{r}1.1 \% \\
(3.6 \%) \\
\end{array}$ & 612 \\
\hline Leisure & 374 & $55.6 \%$ & 206 & $\begin{array}{r}30.6 \% \\
(68.9 \%) \\
\end{array}$ & 57 & $\begin{array}{r}8.5 \% \\
(19.1 \%) \\
\end{array}$ & 36 & $\begin{array}{r}5.3 \% \\
(12.0 \%) \\
\end{array}$ & 673 \\
\hline Maintenance & 387 & $59.3 \%$ & 198 & $\begin{array}{r}30.3 \% \\
(74.4 \%) \\
\end{array}$ & 28 & $\begin{array}{r}4.3 \% \\
(10.5 \%)\end{array}$ & 40 & $\begin{array}{r}6.1 \% \\
(15.0 \%)\end{array}$ & 653 \\
\hline Other & 206 & $87.3 \%$ & 11 & $\begin{array}{r}4.7 \% \\
(36.7 \%) \\
\end{array}$ & 1 & $\begin{array}{r}0.4 \% \\
(3.3 \%) \\
\end{array}$ & 18 & $\begin{array}{r}7.6 \% \\
(60.0 \%) \\
\end{array}$ & 236 \\
\hline Total & 1384 & $63.7 \%$ & 585 & $\begin{array}{r}26.9 \% \\
(74.1 \%)\end{array}$ & 104 & $\begin{array}{r}4.8 \% \\
(13.2 \%)\end{array}$ & 101 & $\begin{array}{r}4.6 \% \\
(12.8 \%)\end{array}$ & 2174 \\
\hline
\end{tabular}

\subsection{Frequency of travel companions by transport mode}

The transport mode greatly affects whether travel occurs. There is a substantial difference between the two cities regarding solo trips by car, which are substantially more frequent in Utrecht than in Beijing. One possible reason is that cars represent a popular mode of transport for non-work travel in Utrecht but are a luxury in Beijing. According to the World Bank, in 2008, motor vehicles numbered 523 per 1,000 people in the Netherlands, whereas in China, this figure
CULTURE, COMPANIONSHIP AND ACTIVITY-TRAVEL

Yanwei Chai

Table 3. Frequency and percentage of travel companions in Beijing and Utrecht Italics in parentheses indicate percentages of accompanied situations.

Source: own work. 
CULTURE, COMPANIONSHIP AND ACTIVITY-TRAVEL

Yanwei Chai

Table 4. Frequency and percentage of travel companions by transportation mode in Beijing and Utrecht

Source: own work. was 37 (The World Bank, 2008). Although the number of motor vehicles has increased rapidly in China, it reached 100 per 1,000 people for the first time in 2014 (National Bureau of Statistics, 2014). Traveling with friends by car occurs frequently in Beijing, resulting in a high percentage in the corresponding total row (Table 4). People in Beijing spend more time with family members while using public transport. One possible reason is that the availability and promotion of public transportation has created a strong dependency among Chinese people, particularly in low-income groups, for long-distance trips. Additionally, traveling with friends may occur when people move from one outdoor location to another. Neighbors are not identified in a separate category but are integrated into the friends category. More frequent trips with friends are thus likely a result of living in physical proximity (Wellman and Wortley, 1990). More than $60 \%$ of traveling by car occurs with core family members in Beijing, indicating that cars represent a mode in which people spend time with family members.

The results regarding travel companions by transportation mode are in line with the activity type results, which both indicate that society is more individualistic in Utrecht than Beijing. Generally, cars represent luxury products. The lower ownership rate leads to more collective trips in Beijing, whereas cars represent a common mode of transport in Utrecht because of the high ownership rate, resulting in more solo trips. The use of public transportation encourages collective trips to a certain extent in Beijing because of the prioritization of public transport (Beijing Transportation Research Center, 2007; Hao et al., 2006).

\begin{tabular}{|c|c|c|c|c|c|c|c|c|c|}
\hline & \multicolumn{2}{|l|}{ Alone } & \multicolumn{2}{|c|}{ Nuclear family } & \multicolumn{2}{|c|}{ Other family } & \multicolumn{2}{|c|}{ Friends } & \multirow{2}{*}{ Total } \\
\hline & Freq. & Per. & Freq. & Per. & Freq. & Per. & Freq. & Per. & \\
\hline \multicolumn{10}{|c|}{ BEIJING } \\
\hline Pub trans & 113 & $39.8 \%$ & 116 & $\begin{array}{r}40.8 \% \\
(67.8 \%)\end{array}$ & 11 & $\begin{array}{r}3.9 \% \\
(6.4 \%)\end{array}$ & 44 & $\begin{array}{r}15.5 \% \\
(25.7 \%)\end{array}$ & 284 \\
\hline Car & 56 & $16.9 \%$ & 215 & $\begin{array}{r}64.8 \% \\
(77.9 \%)\end{array}$ & 3 & $\begin{array}{r}0.9 \% \\
(1.1 \%)\end{array}$ & 58 & $\begin{array}{r}17.5 \% \\
(21.0 \%)\end{array}$ & 332 \\
\hline Bike & 152 & $56.3 \%$ & 95 & $\begin{array}{r}35.2 \% \\
(80.5 \%)\end{array}$ & 1 & $\begin{array}{r}0.4 \% \\
(0.8 \%)\end{array}$ & 22 & $\begin{array}{r}8.1 \% \\
(18.6 \%)\end{array}$ & 270 \\
\hline Walk & 406 & $44.4 \%$ & 324 & $\begin{array}{r}35.4 \% \\
(63.7 \%)\end{array}$ & 17 & $\begin{array}{r}1.9 \% \\
(3.3 \%)\end{array}$ & 168 & $\begin{array}{r}18.4 \% \\
(33.0 \%)\end{array}$ & 915 \\
\hline Total & 727 & $40.4 \%$ & 750 & $\begin{array}{r}41.6 \% \\
(69.8 \%)\end{array}$ & 32 & $\begin{array}{r}1.8 \% \\
(3.0 \%)\end{array}$ & 292 & $\begin{array}{r}16.2 \% \\
(27.2 \%)\end{array}$ & 1801 \\
\hline \multicolumn{10}{|c|}{ UTRECHT } \\
\hline Pub trans & 88 & $74.6 \%$ & 10 & $\begin{array}{r}8.5 \% \\
(33.3 \%)\end{array}$ & 7 & $\begin{array}{r}5.9 \% \\
(23.3 \%)\end{array}$ & 13 & $\begin{array}{r}11.0 \% \\
(43.3 \%)\end{array}$ & 118 \\
\hline
\end{tabular}




\begin{tabular}{|c|c|c|c|c|c|c|c|c|c|}
\hline & \multicolumn{2}{|l|}{ Alone } & \multicolumn{2}{|c|}{ Nuclear family } & \multicolumn{2}{|c|}{ Other family } & \multicolumn{2}{|c|}{ Friends } & \multirow{2}{*}{ Tota } \\
\hline & Freq. & Per. & Freq. & Per. & Freq. & Per. & Freq. & Per. & \\
\hline Car & 646 & $58.3 \%$ & 344 & $\begin{array}{r}31.0 \% \\
(74.3 \%) \\
\end{array}$ & 80 & $\begin{array}{r}7.2 \% \\
(17.3 \%) \\
\end{array}$ & 39 & $\begin{array}{r}3.5 \% \\
(8.4 \%) \\
\end{array}$ & 1109 \\
\hline Bike & 435 & $71.7 \%$ & 150 & $\begin{array}{r}24.7 \% \\
(87.2 \%) \\
\end{array}$ & 8 & $\begin{array}{r}1.3 \% \\
(4.7 \%) \\
\end{array}$ & 14 & $\begin{array}{r}2.3 \% \\
(8.1 \%) \\
\end{array}$ & 607 \\
\hline Walk & 215 & $63.2 \%$ & 81 & $\begin{array}{r}23.8 \% \\
(64.8 \%)\end{array}$ & 9 & $\begin{array}{r}2.6 \% \\
(7.2 \%)\end{array}$ & 35 & $\begin{array}{r}10.3 \% \\
(28.0 \%)\end{array}$ & 340 \\
\hline Total & 1384 & $63.7 \%$ & 585 & $\begin{array}{r}26.9 \% \\
(74.1 \%) \\
\end{array}$ & 104 & $\begin{array}{r}4.8 \% \\
(13.2 \%) \\
\end{array}$ & 101 & $\begin{array}{r}4.6 \% \\
(12.8 \%) \\
\end{array}$ & 2174 \\
\hline
\end{tabular}

CULTURE, COMPANIONSHIP AND ACTIVITY-TRAVEL

Yanwei Chai

Table 4. Continued

\section{Model analysis of travel companion choice}

We investigate the joint effects of demographic and behavioral characteristics on travel companions. The dependent variable is the companions with whom people conduct out-of-home trips (travel companions). A multi-nominal logit model (MNL) is used to estimate the effects in Beijing and Utrecht, respectively, and the "alone" alternative is chosen as the reference category (Table 5). Male and old age impact the propensity for joint trips only in Beijing. Household structure and the presence of young children substantially impact joint trips with family members, especially with core family members, in both cities. Travel purpose is an important factor relating to joint trips. A living environment characterized by high residential density slightly increases the number of trips with friends only in Beijing.

As expected, men tend to travel accompanied less frequently than women in Beijing. One reason is that women may be more likely to provide emotional support to reduce loneliness and anxiety (Wellman and Wortley, 1990). Another reason is that women have more responsibilities related to the household (Cao and Chai, 2007), such as accompanying children and caring for elders. Gender differences are not distinct in Utrecht because the concept of gender equality is more widespread, as reported by previous studies stating that although the Netherlands has relatively low levels of female employment (the rate of fulltime female labor force participation is $45.8 \%$, according to Ruppanner (2010), people have modern attitudes toward individualistic and egalitarian values. These phenomena promote similar social lifestyles between men and women.

Age more strongly affects companionship in Beijing than in Utrecht. People tend to make more solo trips as they age in Beijing but more frequently travel accompanied with friends when older than 50. Relative to with trips with other family members, the number of trips involving core family members significantly decreases as age increases. An individual's social network narrows and focuses on partners or children after marriage and the birth of the first child, which occurs most frequently in 30- to 40-year-old people in China. The social circle 
CULTURE, COMPANIONSHIP AND ACTIVITY-TRAVEL

Yanwei Chai then broadens for people over 50 because their children have become adults, as indicated by the small increase in the number of trips with friends. Age has a slight impact on joint trips with core family members but little impact on trips with other family members and friends in Utrecht. This may be because a good welfare system ensures self-support later in life in the Netherlands (Ng, 2004). Thus, travel habits may be stable to a certain extent.

Household structure significantly affects travel companionship in both cities. People in couples and with core family members perform more trips with their partners or children both in Beijing and Utrecht because such people have more household responsibilities than single people. This supports previous findings regarding the influence of age. Another reason could be that core family members have the same departure point, which facilities car sharing. Households with couples and core family structures in Utrecht travel slightly less frequently with extended family members than in Beijing. This could relate to the differing cultural backgrounds. Strong family beliefs in China encompass caregiving for young children and physical care for elders (Zhan and Montgomery, 2003). Because of the ingrained concept of reciprocity, healthy Chinese elders may provide voluntary support for the care of grandchildren (Leung, 2010), resulting in no significant reduction in joint trips with other family members. However, people in Utrecht are weakly tied to extended family members, especially when shouldering more household responsibilities, leading to a sharp reduction of joint trips with this group. The presence of children below 12 years of age positively affects joint trips in both Beijing and Utrecht because these children are not yet independent and must be accompanied by parents.

The effects of income and education exhibit varied patterns in Beijing and Utrecht. Income does not significantly impact the areas of study in the two cities, except for middle-income individuals accompanied by core family members. Middle-income individuals tend to travel more with core family members, which may be related to two factors. First, high-income individuals have more freedom or can exist independently without the support of others. Second, low-income individuals face life stresses, resulting in high levels of temporal constraints. Higher education levels in Beijing promote travel with core family but limit that with extended family.

We use the ownership of a household car, possession of a driving license and working hours per week to measure the degree of restriction on joint trips. The ownership of a household car negatively impacts joint trips in both Beijing and Utrecht and increases independent trips in urban daily life. The possession of a driving license positively affects joint trips in Beijing but negatively affects joint trips in Utrecht. As Table 1 shows, half of the sample have driving licenses in Beijing, whereas over $90 \%$ have licenses in Utrecht. The substantial number of people without driving licenses in Beijing may use alternative modes of transport, 
such as walking or public transportation, increasing the opportunities for companions to join (Clark and Scott, 2013). Driving a car is a basic and common skill in Utrecht and is accompanied by a high rate of car ownership, which encourages independent trips. Working hours per week does not significantly AND ACTIVITY-TRAVEL affect joint trip decision-making, although we hypothesize it is a dominant factor influencing temporal constraints.

Travel purpose has similar impacts in Beijing and Utrecht. Compared with shopping, leisure positively affects travel with core family members and friends in Beijing. Therefore, leisure or social activities are important modes of sustaining interactions with broad social circles, and they provide opportunities to build a personalized social network in Beijing. In Utrecht, leisure may occur with family and friends. Interestingly, however, maintenance tends to be performed with friends. Possible reasons for this include the following: First, traveling for necessary personal purposes, such as sleep or personal care, always happens after overnighting, which is affiliated with a social purpose. Second, traveling for childcare or obligatory household tasks may involve friends (for people such as housewives). Third, traveling to retrieve or pick up people and items is likely conducted within the friend circle.

Regarding population heterogeneity, we compare the ratios of coefficients (leisure-purpose trips with household structure) between the Beijing and Utrecht groups. The ratios of core family member companions on leisure trips are balanced between household types in both Beijing and Utrecht, and all coefficients are approximately 0.1 . However, the ratio of leisure trips accompanied by other family members is 0.32 for the nuclear household category in Beijing but 5.21 in Utrecht. This indicates close ties with the extended family circle in China, even for leisure or social trips. For couples and core households, people in Beijing have substantially more interactions with friends than people in Utrecht. The related ratios in Beijing exceed 100, while those in Utrecht are lower than 10. Thus, friends are the core group accompanying leisure trips more frequently in Beijing than in Utrecht.

Transport mode is related to companion choice. Notably, the use of public transport may promote companionship by extended family members to some degree in both Beijing and Utrecht. One reason for this is that long-distance travel for tours may be undertaken using public transportation, allowing families to join (Price and Matthews, 2013). Another reason is that people may choose public transportation when they move from one outdoor location to another. Car use promotes joint travel in Beijing but only promotes family trips in Utrecht. This finding supports the possible explanation for car ownership differences between China and the Netherlands regarding travel companions. Bicycles limit joint travel in Beijing because their high concentration in the transportation environment and the extremely limited cycling space, which is in line with findings indicating 
CULTURE, COMPANIONSHIP AND ACTIVITY-TRAVEL

Yanwei Chai

Table 5. MNL model of travel companions in Beijing and Utrecht Source: own work. that positive changes in the cycling environment or infrastructure can improve the cycling experience and promote cycling with family members (Clayton and Musselwhile, 2013).

A further analysis compares coefficient ratios of leisure trips with transport mode. If traveling by public transportation, this analysis shows a substantially lower probability in Beijing (-13.76) than in Utrecht (-6.51). Thus, people tend not to choose friends as companions when using the metro or bus. The degree to which this occurs varies between Beijing and Utrecht. Additionally, travel habits by car differ between the two cities. The probability of traveling with other family members in Beijing (3.25) is higher than that in Utrecht (3.25). Cars are used as a mode of shared transport for an extensive range of household members in Beijing, where car use must be allocated via a complex process (Ho and Mulley, 2013).

We hypothesize that density influences opportunities related to joint travels. However, the effect was not as significant as expected, possibly because of indirect influences related to activity motivation.

\begin{tabular}{|c|c|c|c|c|c|c|c|c|}
\hline & & $\begin{array}{l}\text { Core } \\
\text { family }\end{array}$ & Ext family & Friend & & Core family & Ext family & Friend \\
\hline & & \multicolumn{4}{|c|}{ BEIJING } & \multicolumn{3}{|c|}{ UTRECHT } \\
\hline \multirow{2}{*}{ Gender } & Male & $-0.206^{*}$ & $-0.970 * *$ & -0.246 & & 0.189 & -0.228 & -0.048 \\
\hline & Female & 0 & 0 & 0 & & 0 & 0 & 0 \\
\hline \multirow{5}{*}{ Age } & $20-29$ & 0 & 0 & 0 & & 0 & 0 & 0 \\
\hline & $30-39$ & $-0.514 * *$ & -0.573 & $-1.299 * * *$ & & -0.209 & -0.535 & 0.083 \\
\hline & $40-49$ & $-0.597 * *$ & -1.272 & $-0.865 * * *$ & & -0.234 & -0.213 & -0.169 \\
\hline & $50-59$ & $-1.072 * * *$ & $-2.193 * *$ & $-1.178^{* * *}$ & & $-0.643 * *$ & -0.403 & $-0.848^{*}$ \\
\hline & $60+$ & $-0.592^{*}$ & -0.594 & $-0.944^{* *} *$ & & $-0.680 * *$ & -0.119 & 0.246 \\
\hline \multirow{4}{*}{$\begin{array}{l}\text { House- } \\
\text { hold } \\
\text { structure }\end{array}$} & Single & 0 & 0 & 0 & & 0 & 0 & 0 \\
\hline & Couple & $2.091 * * *$ & -0.743 & 0.011 & & $3.938 * * *$ & $0.597 *$ & 0.421 \\
\hline & $\begin{array}{l}\text { Core } \\
\text { family }\end{array}$ & $1.979 * * *$ & 0.921 & 0.009 & & $3.699 * * *$ & -0.253 & 0.166 \\
\hline & Other & $2.014 * * *$ & 0.114 & -0.181 & & $2.967 * * *$ & -0.977 & $0.885^{*}$ \\
\hline Children & Below 12 & $0.456^{* *}$ & -0.379 & 0.135 & & $0.571^{* * * *}$ & -0.977 & 0.885 \\
\hline \multirow{5}{*}{$\begin{array}{l}\text { House- } \\
\text { hold } \\
\text { income }\end{array}$} & $300-$ & 0 & 0 & 0 & $2000-$ & 0 & 0 & 0 \\
\hline & $300-500$ & -0.069 & -0.201 & $0.377^{*}$ & $\begin{array}{l}2000- \\
3000 \\
\end{array}$ & -0.119 & -0.977 & -0.496 \\
\hline & $500-700$ & -0.114 & 0.646 & 0.272 & $\begin{array}{l}3000- \\
4000\end{array}$ & $0.365^{*}$ & 0.155 & 0.003 \\
\hline & $700-1000$ & $0.728^{* * * *}$ & -0.839 & 0.289 & $4000+$ & 0.073 & -0.33 & -0.51 \\
\hline & $1000+$ & 0.163 & -0.873 & 0.096 & & & & \\
\hline
\end{tabular}




\begin{tabular}{|c|c|c|c|c|c|c|c|}
\hline & & $\begin{array}{l}\text { Core } \\
\text { family }\end{array}$ & Ext family & Friend & Core family & Ext family & Friend \\
\hline & & \multicolumn{3}{|c|}{ BEIJING } & \multicolumn{3}{|c|}{ UTRECHT } \\
\hline \multirow{3}{*}{$\begin{array}{l}\text { Educa- } \\
\text { tion }\end{array}$} & Low & 0 & 0 & 0 & 0 & 0 & 0 \\
\hline & Middle & 0.193 & -1.581 & $-0.183^{* *}$ & 0.336 & 0.527 & 0.424 \\
\hline & High & 0.182 & -1.038 & 0.065 & 0.313 & 0.542 & 0.923 \\
\hline $\begin{array}{l}\text { House- } \\
\text { hold car }\end{array}$ & & $-0.403^{* * *} *$ & 0.324 & $-0.414^{* *}$ & -0.098 & $-0.359 *$ & 0.191 \\
\hline $\begin{array}{l}\text { Driving } \\
\text { license }\end{array}$ & & 0.159 & -0.704 & $0.377 * *$ & $-0.611 * *$ & $-1.456^{* * *}$ & -0.659 \\
\hline $\begin{array}{l}\text { Working } \\
\text { hour }\end{array}$ & & -0.002 & 0.008 & 0.003 & -0.006 & -0.007 & 0.013 \\
\hline \multirow{4}{*}{$\begin{array}{l}\text { Travel } \\
\text { purpose }\end{array}$} & Shop & 0 & 0 & 0 & 0 & 0 & 0 \\
\hline & Leisure & $0.350^{* * * *}$ & 0.299 & $1.417 * * *$ & $0.412^{* * *}$ & $1.317^{* * *}$ & $1.776^{* * *}$ \\
\hline & Mainten & -0.163 & -0.595 & 0.330 & 0.064 & $0.558 *$ & $1.863 * * *$ \\
\hline & Other & 0.199 & -32.275 & 0.601 & $-2.171 * * *$ & $-2.213 * *$ & $1.546^{* * *}$ \\
\hline \multirow{4}{*}{$\begin{array}{l}\text { Travel } \\
\text { mode }\end{array}$} & Pub trans & 0.209 & 0.696 & -0.103 & -0.632 & $0.979 * *$ & -0.273 \\
\hline & Car & $1.637 * * *$ & 0.092 & $0.996 * * *$ & $0.458 * * *$ & $1.368 * * *$ & $-1.133^{*} * *$ \\
\hline & Bike & -0.104 & -1.618 & $-0.701 * * *$ & -0.092 & 1.368 & $-1.668 * * *$ \\
\hline & Walk & 0 & 0 & 0 & 0 & 0 & 0 \\
\hline $\begin{array}{l}\text { Residen- } \\
\text { tial area }\end{array}$ & $\begin{array}{l}\text { Pop } \\
\text { density }\end{array}$ & 0.007 & -0.009 & $-0.017^{* *}$ & 0.024 & -0.027 & -0.005 \\
\hline \multirow[t]{2}{*}{ Cons } & & -2.005 & -0.841 & -0.690 & -4.028 & -2.503 & -3.791 \\
\hline & & $\begin{array}{l}\text { Obs } \\
\text { No. }=1801\end{array}$ & $\begin{array}{l}\text { Log } \\
\text { likelihood= } \\
-1760.7239\end{array}$ & $\begin{array}{l}\mathrm{R} 2= \\
0.1093\end{array}$ & $\begin{array}{l}\text { Obs } \\
\text { No. }=2174\end{array}$ & $\begin{array}{l}\text { Log likeli- } \\
\text { hood }= \\
-1679.2648\end{array}$ & $\begin{array}{l}\mathrm{R} 2= \\
0.1683\end{array}$ \\
\hline
\end{tabular}

CULTURE, COMPANIONSHIP AND ACTIVITY-TRAVEL

Yanwei Chai

Table 5. Continued

\section{Conclusion and discussion}

This paper investigates the impacts of cultural differences on the choice of companions in daily activity-travel behavior between China and the Netherlands and how these impacts differ according to socio-demographics, activity type and transport mode. An empirical study based on activity diary surveys collected in Beijing and Utrecht finds significant cultural context factors affecting activitytravel behavior. People in Beijing perform more activities and trips with family members, reflecting the collective culture and strong family beliefs in Chinese society, which is consistent with previous studies stating that a Confucian moral understanding is dominant in modern China (Fan, 2011). In comparison, people in Utrecht tend to perform activities and travel alone more frequently. If accompanied, they likely choose friends as activity companions but core family members as travel companions. These findings are in accordance with individualistic behavior, which is prevalent in Western societies (Beck, 1996; Dogan, 2002). Moreover, sociodemographics, particularly those relating to life cycle status, are strongly 
CULTURE, COMPANIONSHIP AND ACTIVITY-TRAVEL

Yanwei Chai related to companion choice. Older men tend to take more trips alone, whereas people who are members of couples or core families with young children tend to perform activities or trips with other family members. Regarding the influence of travel purpose and transport mode, leisure or social purposes encourage joint travel, particularly with friends, and traveling by car promotes family companions in both cities. Traveling by car promotes friends as companions in Beijing to a greater extent than in Utrecht.

This behavioral comparison is valuable when addressing transportation policy issues. The differences in travel companion choice between Beijing and Utrecht reflects cultural gaps between East and West. Thus, models addressing travel demand must consider cultural context (Aldred and Jungnickel, 2014; Lin and Wang, 2014). Assuming a similar population, the high proportion of joint travel in China may decrease the total travel demand compared with, for example, the Netherlands in the West. This paper also contributes to the literature by indicating that ride sharing is not only restricted to car sharing but also extends to other modes of transport. Though indirectly, existing studies show that the high percentage of ride sharing could increase the use of alternative modes of transport (Katzev, 2002) and may affect travel demand estimations.

The role of the social network and its effect on travel behavior warrant attention regarding the application of transportation policies. On the one hand, a car-sharing policy (as an efficient and low-carbon mode of transport) is closely related to travel companionship. Generally, car sharing occurs first among existing social networks, particularly among family members for leisure purposes (Gärling et al., 2000). Car sharing then gradually extends to include colleagues or even strangers for work purposes. In this context, the Chinese population presents patterns similar to those associated with family-oriented companionship. However, shifting towards public carsharing practices may be difficult given the Confucian-related family-only trust norm. Thus, transportation policy-making must consider cultural and social contexts. On the other hand, to encourage car sharing, high-occupancy vehicle lanes have been implemented in some Western countries. Social networks and likely travel companions should be considered when determining the impact of a special lane policy. Knowledge regarding travel partners, their roles in the social network and their spatial locations are crucial in improving policy design and related effects (Lin and Wang, 2014).

This study provides new information on the cultural differences in activitytravel behavior and promotes future analyses. First, although car use appears to promote joint traveling, it only encourages interaction between people who know each other and actually reduces opportunities to communicate with strangers. In contrast, cycling and walking, which occur in open situations, enable interaction with strangers. These slow transportation modes promote both social involvement and low-carbon development. Second, the dualistic construct of individualism 
and collectivism must be clearly reconsidered in future work. Collectivist tendencies can vary according to the individual, such as family-collectivist and friend-collectivist (Hui and Triandis, 1986). Thus, we cannot draw a simple conclusion regarding to which culture is definitively more collective. Additionally, obligation and intention are difficult to separate from the initial purpose (desiring or complying) (Hui, 1988). For example, activities or travel with core family members may be undertaken not only because of the desire to accompany a partner or children but also because of an obligation to care for them. This explains why companionship by core family members is common in Western countries, where core family members feel strong family obligations (Oyserman et al., 2002).

Several limitations of this study should be discussed. First, the empirical data are relatively old. Although the study results show the validity and reliability of companion choice comparison, the surveys were conducted in 2007. The activitytravel behavior in urban daily life might have changed since then, particularly in China. Second, we use Beijing and Utrecht as case studies to explore the differences between China and the Netherlands. Beijing and Utrecht may differ in several aspects, including geography, built environment, weather patterns, and available transport modes, which could influence the results. Third, the dualistic construct of individualism and collectivism must be clearly reconsidered in future work. Collectivist tendencies can vary among target persons, such as familycollectivist and friend-collectivist (Hui and Triandis, 1986), and thus, we cannot draw a simple conclusion regarding which culture is definitely more collective.

\section{Notes}

[1] If trips simultaneously include two or three categories, the final category is defined as the one presenting the highest level of individualism. For example, if a person travels with core family members and friends, we define this trip as companionship with friends. This is because friends who live outside the household may have priority in all matters in terms of coordinating their schedules.

\section{References}

Aldred, R., Jungnickel, K. (2014), „Why culture matters for transport policy: the case of cycling in the UK", Journal of Transport Geography, Vol. 34, pp. 78-87. DOI: $10.1016 /$ j.jtrangeo.2013.11.004

Bauman, Z. (2005), Liquid life, UK: Polity Press, Cambridge.

Beck, U. (1996), The reinvention of politics: rethinking modernity in the global social order, London: Polity Press, London.

Beijing Transport Research Center (2007), Beijing transport annual report, available at: http://www.bjjtw.gov.cn/gzdt/ghjh/tjxx/201207/P020130712555604597022.pdf (accessed 1 July 2012).

Cao, X., Chai, Y. (2007), „Gender role-based differences in time allocation: Case study of Shenzhen, China", Journal of the Transportation Research Board, 2014, pp. 58-66. DOI: $10.3141 / 2014-08$ 
CULTURE, COMPANIONSHIP AND ACTIVITY-TRAVEL

Yanwei Chai
Carrasco, J., Miller, E.J. (2009), „The social dimension in action: A multilevel, personal networks model of social activity frequency between individuals", Transportation Research Part A: Policy and Practice, Vol. 43, 90-104. DOI:10.1016/j.tra.2008.06.006

Carrasco, J.A., Miller, E.J. (2006), „Exploring the propensity to perform social activities: a social network approach", Transportation, Vol. 33, pp. 463-480. DOI:10.1007/ s11116-006-8074-z

Clark, A.F., Scott, D.M. (2013), ,Does the social environment influence active travel? An investigation of walking in Hamilton, Canada", Journal of Transport Geography, Vol. 31, pp. 278-285. DOI: 10.1016/j.jtrangeo.2013.06.005

Clayton, W., Musselwhite, C. (2013), ,Exploring changes to cycle infrastructure to improve the experience of cycling for families", Journal of Transport Geography, Vol. 33, pp. 54-61. DOI: 10.1016/j.jtrangeo.2013.09.003

Dejbakhsh, S., Arrowsmith, C., Jackson, M. (2011), „Cultural influence on spatial behaviour",

Dogan, M. (2002), „Accelerated decline of religious beliefs in Europe”, Comparative Sociology, Vol. 1, pp. 127-149. DOI: 10.1163/156913302100418466

Ettema, D., Kwan, M.-P. (2010), „The influence of social ties on social and recreational activity participation of ethnic groups in the Netherlands", $12^{\text {th }}$ WCTR, July 11-15, Lisbon, Portugal.

Ettema, D., Zwartbol, D. (2013), „The structure of joint leisure trips: analyzing twoperson leisure trips of Dutch students", Journal of Transport Geography, Vol. 31, pp. 216-225. DOI: 10.1016/j.jtrangeo.2013.05.006

Fan, R. (2011), ,Introduction: the rise of authentic Confucianism”, in: Fan, R. (Ed.), Renaissance of Confucianism in contemporary China. DOI: 10.1007/978-94-0071542-4_1

Fan, Y., Khattak, A.J. (2009), ,Does urban form matter in solo and joint activity engagement?",

Fellows, N.T., Pitfield, D.E. (2000), „An economic and operational evaluation of urban carsharing", Transportation Research Part D: Transport and Environment, Vol. 5 No. 1, 1-10. DOI: 10.1016/S1361-9209(99)00016-4

Feng, J., Dijst, M., Prillwitz, J., Wissink, B. (2013), ,,Travel time and distance in international perspective: a comparison between Nanjing (China) and the Randstad (The Netherlands)", Urban Studies, Vol. 50, pp. 2993-3010. DOI: 10.1177/0042098013482504

Fiske, J. (1992), „Cultural studies and the culture of everyday life”, in: Grossberg, L.N.,

Gärling, T., Gärling, A., Johansson, A. (2000), „Household choices of car-use reduction measure",

Geoforum, Vol. 39, pp. 1362-1377. DOI: 10.1016/j.geoforum.2007.11.005

Gliebe, J. P., Koppelman, F.S. (2002), „A model of joint activity participation between household members", Transportation, Vol. 29, pp. 49-72. DOI: 10.1023/A:1012995509777

Hanson, S. (2000), „Transportation: hooked on speed, eyeing sustainability”, in: Sheppard, E., Barnes T.J. (Eds.), A companion to economic geography, Blackwell Publishers, Malden.

Hao, J., Hu, J., Fu, L. (2006), „Controlling vehicular emissions in Beijing during the last decade", Transportation Research Part A: Policy and Practice, Vol. 40, pp. 639-651. 
Harvey, A.S., Taylor, M.E. (2000), „Activity settings and travel behavior: A social contact perspective", Transportation, Vol. 27, pp. 53-73. DOI: 10.1023/A:1005207320044

Ho, C., Mulley, C. (2013), ,Tour-based mode choice of joint household travel patterns on weekend and weekday", Transportation, Vol. 40, pp. 789-811. DOI: 10.1007/ s11116-013-9479-0

Houtman, D., Mascini, P. (2002), „Why do churches become empty, which new age grows? Secularization and religious change in the Netherlands", Journal for the Scientific Study of Religion, Vol. 41, pp. 455-473.

http://data.worldbank.org/indicator/IS.VEH.NVEH.P3 (accessed 27 August 2011).

Hubers, C., Schwanen, T., Dijst, M. (2011), „Coordinating everyday life in the Netherlands: A holistic quantitative approach to the analysis of ICT-related and other work-life balance strategies", Geografiska Annaler: Series B, Human Geography, Vol. 93, pp. 57-80. DOI: 10.1111/j.1468-0467.2011.00361.x

Hui, C. H. (1988), „Measurement of individualism-collectivism”, Journal of Research in Personality, Vol. 22, pp. 17-36. DOI: 10.1016/0092-6566(88)90022-0

Hui, C.H., Triandis, H.C. (1986), „Individualism-collectivism: A study of cross-cultural researchers", Journal of Cross-Cultural Psychology, Vol. 17, pp. 225-248. DOI: 10. 1177/0022002186017002006.

Inglehart, R., Baker, W.E. (2000), „Modernization, cultural change, and the persistence of traditional values", American Sociological Review, Vol. 65, pp. 19-51. DOI: $10.2307 / 2657288$

Katzev, R. (2003), „Car-sharing: A new approach to urban transportation problems”, Analyses of Social Issues and Public Policy, Vol. 3, pp. 65-86. DOI: 10.1111/j.15302415.2003.00015.x

Komter, A.E., Knijn, T.C.M. (2006), „The strength of family ties”, in: Dykstra, P.A., Kalmijn, M., Knijn, T.C.M., Komter, A.E., Liefbroer, A.C., Mulder, C.H. (Eds.), Family solidarity in the Netherlands, Dutch University Press, Amsterdam.

Landscape and Urban Planning, Vol. 92, pp. 199-209. DOI: 10.1016/j.landurbplan.2009.05.006

Lee, Y. Hickman, M., Washington, S. (2007), „Household type and structure, time-use pattern, and trip-chaining behavior", Transportation Research Part A: Policy and Practice, Vol. 41, pp. 1004-1020.

Leung, K. (2010), „Beliefs in Chinese culture”, in: Bond, M.H. (Ed.), The Oxford handbook of Chinese psychology, Oxford University Press, Oxford.

Lin, T., Wang, D. (2014), ,Social networks and joint/solo activity-travel behawior”, Transportation Research Part A: Policy and Practice, Vol. 68, pp. 18-31. DOI: 10.1016/j. tra.2014.04.011

Manrai, L.A., Manrai, A.K. (2011), „Hofstede's cultural dimensions and tourist behaviors: a review and conceptual framework", Journal of Economics, Finance and Administrative Science, Vol. 16, pp. 23-48.

Miller, E.J., Roorda, M.J., Carrasco, J.A. (2005), „A tour-based model of travel mode choice”, Transportation, Vol. 32, pp. 399-422. DOI: 10.1007/s11116-004-7962-3

Moore, J., Carrasco, J., Tudela, A. (2013), „Exploring the links between personal networks, time use, and the spatial distribution of social contacts", Transportation, Vol. 40, pp. 773-788. DOI: $10.1007 / \mathrm{s} 11116-013-9467-4$
CULTURE, COMPANIONSHIP AND ACTIVITY-TRAVEL

Yanwei Chai 

COMPANIONSHIP

Yanwei Chai
CULTURE, AND ACTIVITY-TRAVEL

National Bureau of Statistics (2014), The national economic and social development statistical bulletin for China, available at: http://www.stats.gov.cn/tjsj/zxfb/201502/ t20150226_685799.html (accessed 26 February 2015).

Neison, T.D. (Ed.), Ageism: stereotyping and prejudice against older persons, MIT Press, Cambridge.

Neutens, T., Schwanen, T., Witlox, F., De Maeyer, P.D. (2008), „My Space or your space? Towards a measure of joint accessibility", Computers, Environment and Urban Systems, Vol. 32, pp. 331-342. DOI: 10.1016/j.compenvurbsys.2008.06.001

$\mathrm{Ng}, \mathrm{S}$. H. (2004), „Will families support their elders? Answers from across cultures”, in:

Oyserman, D., Coon, H.M., Kemmelmeier, M. (2002), „Rethinking individualism and collectivism: evaluation of theoretical assumptions and meta-analyses", Psychological Bulletin, Vol. 128, pp. 3-72. DOI: 10.1037/0033-2909.128.1.3

Oyserman, D., Lee, S.W. (2008), „Does culture influence what and how we think? Effects of priming individualism and collectivism", Psychological Bulletin, Vol. 134, pp. 311-342. DOI: 10.1037/0033-2909.134.2.311

Pelzer, P. (2010), „Bicycling as a way of life: A comparative case study of bicycle culture in Portland, OR and Amsterdam", Paper Presented to the $7^{\text {th }}$ Cycling and Society Symposium, Oxford, UK, available at: http://www.tsu.ox.ac.uk/events/100906/ csspelzer-paper.pdf.

Phan, M.B., Blumer, N., Demaiter, E.I. (2009), „Helping hands: neighborhood diversity, deprivation, and reciprocity of support in non-kin networks", Journal of Social and Personal Relationship, Vol. 26, pp. 899-918. DOI: 10.1177/0265407509345655

Price, L., Matthews, B. (2013), „Travel time as quality time: parental attitudes to long distance travel with young children", Journal of Transport Geography, Vol. 32, pp. 49-55. DOI: 10.1016/j.jtrangeo.2013.08.001

Ruppanner, L.E. (2010), „Cross-national reports of housework: an investigation of the gender empowerment measure", Social Science Research, Vol. 39, pp. 963-975. DOI: $10.1016 /$ j.ssresearch.2010.04.002

Schwanen, T. (2008), „Dutch transport geography page”, Journal of Transport Geography, Vol. 16, pp. 447-448. DOI: 10.1016/j.jtrangeo.2008.07.004

Schwanen, T., Dijst, M., Dieleman, F.M. (2002), „A microlevel analysis of residential context and travel time", Environment and Planning A, Vol. 34, pp. 1487-1507. DOI: 10.1068/a34159

Schwanen, T., Ettema, D., Timmermans, H. (2007), „If you pick up the children, I'll do the groceries: spatial differences in between-partner interactions in out-of-home activities", Environment and Planning A, Vol. 39, pp. 2754-2773. DOI: 10.1068/a38491

Schwanen, T., Kwan, M. (2008), „The internet, mobile phone and space-time constraints”,

Schwanen, T., Kwan, M., Ren, F. (2008), „How fixed is fixed? Gendered rigidity of space-time constraints and geographies of everyday activities", Geoforum, Vol. 39, pp. 2109-2121. DOI: 10.1016/j.geoforum.2008.09.002

Sharmeen, F., Ettema, D. (2010), „Whom to hang out with and where? Analysis of the influence of spatial setting on the choice of activity company", proceedings from $12^{\text {th }}$ WCTR. July 11-15, Lisbon, Portugal. 
tion characteristics using the American time use survey", Transportation, Vol. 35, pp. 301-327. DOI: 10.1007/s11116-007-9155-3

The World Bank (2008), World Bank data: motor vehicles (per 1,000 people), available at:

Tourism Geographies, Vol. 13, pp. 91-111. DOI: 10.1080/14616688.2010.516396.

CULTURE,

COMPANIONSHIP AND ACTIVITY-TRAVEL

Transportation Research Part A: Policy and Practice, Vol. 34, pp. 309-320.

Treichler, C. (Eds.), Cultural studies, Routledge, New York.

Walker, K. (1995), ,"Always there for me": friendship patterns and expectations among middle- and working- class men and women", Sociological Forum, 10, 273-296. DOI: $10.1007 / \mathrm{BF} 02095961$.

Wang, D., Chai, Y., Li, F. (2010), „Built environment diversities and activity-travel behavior variations in Beijing, China", Journal of Transport Geography, Vol. 19, pp. 1173-1186.

Wellman, B. (2001), „Physical place and cyberplace: the rise of personalized networking", International Journal of Urban and Regional Research, Vol. 25, pp. 227-252. DOI: $10.1111 / 14682427.00309$.

Wellman, B., Wortley, S. (1990), „Different strokes from different folks: community ties and Social support", American Journal of Sociology, Vol. 96, pp. 558-588. DOI: $10.1086 / 229572$.

Wink, P. (1997), „Beyond ethnic differences: contextualizing the influence of ethnicity on individualism and collectivism”, Journal of Social Issues, Vol. 53, pp. 329-350. DOI: 10.1111/j.1540-4560.1997.tb02446.x

Zhan, H.J., Montgomery, R.J.V. (2003), „Gender and elder care in China: the influence of filial piety and structural constraints", Gender \& Society, Vol. 17, pp. 209-229. DOI: $10.1177 / 08912432022507$. 